\title{
Acidentes e violências na infância e adolescência: fatores de risco e de proteção
}

\author{
Accidents and violence in childhood and adolescence: risk and protective factors
}

Accidentes y violencias en la infancia y adolescencia: factores de riesgo y de protección

\author{
Christine Baccarat de Godoy Martins' \\ ' Universidade Federal de Mato Grosso, Faculdade de Enfermagem, \\ Programa de Mestrado em Enfermagem. Cuiabá-MT, Brasil.
}

Submissão: 11-04-2011Ａprovação: 26-03-2013

\section{RESUMO}

Apontada pelas estatísticas como a terceira causa de mortalidade em nosso país, as causas externas (acidentes e violências) ocasionam um grande impacto com repercussão econômica, social e emocional. Conhecer os fatores relacionados a este evento torna-se essencial, pois possibilita identificar e quebrar a teia que determina a morbimortalidade por causas externas. O estudo busca analisar as publicações existentes sobre os fatores associados aos acidentes e violências, a fim de proporcionar subsídios teóricos para os profissionais em suas práticas. Trata-se de estudo bibliográfico nas bases de dados Lilacs, Medline e Scielo. O conhecimento dos fatores de risco e proteção discutidos ao longo deste texto possibilita subsidiar a prática dos atores sociais engajados na transformação das condições geradoras de acidentes e violências.

Descritores: Causas Externas; Fatores de Risco; Fatores Epidemiológicos; Prevenção de Acidentes; Violência.

\begin{abstract}
Singled out by statistics as the third leading cause of mortality in our country, external causes (accidents and violence) entail a great impact with economic, social and emotional rebound. Knowing the factors related to the event is essential, because it allows identifying and breaking the web that determines morbidity and mortality from external causes. The study aims to analyze the existing publications on the factors associated with accidents and violence, in order to provide theoretical support for professionals in their practices. This is a bibliographical study of the Liliacs, Medline and Scielo databanks. The knowledge of the risk and protection factors discussed in the present study enables subsidize the practice of social actors engaged in transforming the conditions that lead to accidents and violence.
\end{abstract}

Key words: External Causes; Risk Factors; Epidemiologic Factors; Accident Prevention; Violence.

\section{RESUMEN}

Señalada por las estadísticas como la tercera causa de mortalidad en nuestro país las causas externas (accidentes y violencias) producen un gran impacto en el ámbito económico, social y emocional. Conocer los factores relacionados con ese fenómeno se torna esencial, para que puedan ser identificadas las causas y quebrada la secuencia que determina la morbimortalidad por causas externas. En el presente estudio se realizó una búsqueda de las publicaciones existentes sobre los factores asociados a los accidentes y violencias, con la finalidad de ofrecer subsidios teóricos para las prácticas de los profesionales. Se trata de un estudio bibliográfico según las bases de datos Lilacs, Medline y Scielo. El conocimiento de los factores de riesgo y protección discutidos a lo largo de este texto permite auxiliar la práctica de los actores sociales comprometidos en la transformación de las condiciones que generan accidentes y violencias.

Palabras clave: Causas Externas; Factores de Riesgo; Factores Epidemiológicos; Prevención de Accidentes; Violencia. 


\section{INTRODUÇÃO}

Apontada pelas estatísticas como a terceira causa de mortalidade em nosso país, as causas externas (acidentes e violências) ocasionam um impacto que pode ser medido por meio de sua repercussão econômica, social e emocional ${ }^{(1-3)}$, além do reflexo na expectativa de vida ${ }^{(4)}$. As lesões, os traumas e as mortes decorrentes de acidentes e violências geram altos custos, que se traduzem em dias de ausência no trabalho, custos para o sistema de saúde, demanda aos serviços sociais, danos mentais e emocionais incalculáveis para as vítimas e famílias, além da perda de anos potenciais de vida frente aos casos fatais $^{(5)}$.

Em nosso país, é relevante o impacto dos acidentes e violências nos custos hospitalares, uma vez que estas causas ocuparam o sexto lugar em número de internações, e o terceiro lugar no valor total pago pelo SUS, no valor de $\mathrm{R} \$ 155.091 .524,39$ dos cofres públicos, sem falar naquilo que o Brasil deixa de arrecadar com o turismo, em razão do impacto negativo da violência no país ${ }^{(6)}$.

Tão importante quanto conhecer as circunstâncias em que ocorre, torna-se essencial, também, conhecer os fatores relacionados a este evento, pois possibilita identificar e quebrar a teia que acaba determinando os óbitos por causas externas ${ }^{(7)}$. Entretanto, são poucos os estudos que abordam com profundidade os fatores de risco ou de proteção relacionados com acidentes e violências, principalmente na população infanto-juvenil, grupo etário considerado mais vulnerável ${ }^{(8-10)}$.

Frente à magnitude da mortalidade e morbidade por causas externas, principalmente na faixa etária mais jovem (de 0 a 24 anos), mediante a importância de se conhecer os fatores de risco associados a estas causas, o presente estudo buscou recolher, analisar e interpretar as contribuições teóricas já existentes sobre os fatores associados aos acidentes e violências, a fim de proporcionar uma visão global quanto à problemática abordada, fornecendo subsídios teóricos para os profissionais em suas práticas e reunindo um acervo bibliográfico sobre o tema. Neste contexto, este trabalho tem como objetivo analisar as publicações existentes sobre os fatores associados aos acidentes e violências, a fim de proporcionar subsídios teóricos para os profissionais em suas práticas.

\section{METODOLOGIA}

Tratou-se de revisão sistemática de literatura acerca dos fatores associados às causas externas, desenvolvido no período de abril a julho de 2011, mediante pesquisa bibliográfica nas bases de dados Lilacs, Medline e Scielo. Foram adotados como critérios de inclusão: artigos completos disponíveis na biblioteca virtual Bireme e documentos eletrônicos disponíveis online, que abordassem os fatores associados às causas externas, publicados no período de 2000 a 2010. Utilizaram-se como descritores as palavras: causas externas, fatores de risco, fatores associados, acidente e violência, trauma, mortalidade, morbidade, agressão, maus-tratos, infância, adolescência, síndrome da criança maltratada, prevenção de violência; não se fazendo restrição aos idiomas espanhol, inglês e francês.
As publicações, tanto as nacionais quanto as internacionais, foram analisadas segundo o ano de publicação, o tipo de publicação (artigos completos e documentos eletrônicos) e a área em que foram publicadas (especificando os nacionais e internacionais). Além dos aspectos quantitativos em percentuais, foi realizada análise de conteúdo, o que permitiu classificar os fatores de risco e de proteção associados às causas externas.

\section{RESULTADOS}

Foram encontradas 62 publicações que tratavam sobre os fatores de risco e de proteção associados às causas externas, sendo 20 (32,3\%) internacionais e 42 (67,3\%) nacionais. Do total de publicações, $59(95,2 \%)$ são artigos completos, 1 $(1,6 \%)$ manual do Ministério da Saúde e 2 (3,2\%) são relatórios. Das publicações nacionais (42), 40 (95,2\%) são artigos completos, $1(2,4 \%)$ manual e $1(2,4 \%)$ relatório. Das publicações internacionais, $19(95,0 \%)$ são artigos completos e 1 $(5,0 \%)$ relatório.

Entre os artigos nacionais (40), $17(42,5 \%)$ foram publicados em periódico de Saúde Pública, 6 (15,0\%) em periódicos de Pediatria, 5 (12,5\%) em periódico de Epidemiologia, 4 $(10,0 \%)$ em periódico de Enfermagem, 3 (7,\%) em periódico de Psiquiatria / Psicologia, 1 (2,5\%) em periódico de Medicina e $4(10,0 \%)$ em periódicos de outras áreas. Entre os internacionais (19), 5 (26,3\%) foram publicados em periódicos de Pediatria, 5 (26,3\%) em periódicos de Psiquiatria / Psicologia, $2(10,5 \%)$ em periódico de Epidemiologia, 2 (10,5\%) em periódico de Medicina, 2 (10,5\%) em periódico de Trauma, 1 (5,3\%) em periódico de Saúde Pública, 1 (5,3\%) em periódico sobre comportamento e 1 (5,3\%) em periódico de outra área.

O ano de publicação por ordem decrescente foi 2008 (12 $=20,9 \%), 2006(10=16,1 \%), 2005(10=16,1 \%), 2009$ $(9=14,5 \%), 2007(9=14,5 \%), 2004(4=6,4 \%), 2000(4$ $=6,4 \%), 2003(2=3,2 \%), 2002(1=1,6 \%)$ e $2010(1=$ $1,6 \%)$

A análise do conteúdo dos estudos permitiu organizar os fatores de risco e de proteção associados às causas externas segundo está descrito a seguir.

\section{Fatores socioeconômicos}

Entre os diversos fatores associados com a ocorrência das causas externas, os fatores socioeconômicos são frequentemente apontados pelos autores, tais como a renda familiar, a escolaridade materna, a idade materna, número de filhos, entre outros ${ }^{(11-13)}$. Acredita-se que em família com renda baixa, os pais podem não ser capazes de supervisionar adequadamente os filhos, que às vezes são deixados sozinhos ou na companhia de um irmão, para que os pais possam trabalhar. Além disto, crianças que vivem em situação de pobreza podem ser expostas a perigos ambientais diversos tais como estruturas físicas que propiciam o acidente, espaços inadequados para lazer, exposição à rua e suas ameaças entre outros ${ }^{(14)}$. Nesses mesmos espaços sociais os jovens costumam ser recrutados para o exercício de atividades ilegais, muitas vezes transformando-se em agentes de violência (contra seus companheiros e parceiras) e 
em vítimas ${ }^{(15)}$. Estudo de coorte em Ribeirão Preto identificou que entre as mortes por causa externa entre adolescentes, os fatores socioeconômicos influenciaram nestas mortes ${ }^{(9)}$.

\section{Constituição/estrutura familiar}

Especificamente em relação aos acidentes (causas não intencionais), a constituição familiar tem sido apontada como fator associado. Um estudo de coorte prospectivo com crianças inglesas concluiu que aquelas que residiam com pais substitutos (madrasta ou padrasto) foram vítimas de acidentes como queimaduras, quedas e aspiração de corpo estranho numa proporção bem maior em relação às crianças que residiam com os pais biológicos ${ }^{(16)}$. O estudo também aponta como fatores associados o nível de escolaridade da mãe, hiperatividade da criança, depressão materna e fatores relativos à maternidade como a gravidez na adolescência.

Em relação à violência intencional, o fato de sofrer maus-tratos ou negligência na infância parece guardar relação direta com a prática de atos violentos na adolescência ou fase adulta, podendo a criança/adolescente/jovem desenvolver um comportamento agressivo a partir de um ambiente hostil(17-18) .

\section{Ambiente doméstico}

O ambiente doméstico pode contribuir para desencadear diversos tipos de acidentes, pois a residência apresenta grande número de produtos e situações facilitadoras para a ocorrência desses eventos ${ }^{(19)}$.

Neste sentido, os fatores de risco relativos ao ambiente doméstico são classificados em QUÍMICOS (medicamentos, produtos de higiene e limpeza); FÍSICOS (líquidos quentes); AMBIENTAIS (locais perigosos como janelas, escadas, elevadores, banheiro, áreas de serviço, jardins, piscinas, cozinha com objetos pérfuro-cortantes), BIOLÓGICOS (plantas, animais domésticos, animais peçonhentos, insetos, roedores) e ESTRUTURAIS (formação da família, cultura, estilo de vida, hábitos, crenças) ${ }^{(20)}$.

\section{Idade e características de personalidade da vítima}

Além dos fatores descritos acima, a idade também parece guardar estreita relação com as causas externas, pois os adolescentes e os jovens têm sido freqüentemente identificados como as principais vítimas de acidentes e violências. Fatores como inexperiência, busca de emoções, prazer em experimentar situações de risco, impulsividade e o acesso a armas, álcool, drogas, parecem estar associados aos comportamentos deste grupo etário ${ }^{(21)}$.

Diversos estudos têm demonstrado que os acidentes domésticos guardam relação, principalmente, com a idade da criança, sua etapa de desenvolvimento psicomotor e situações facilitadoras de risco, pois devido ao incompleto desenvolvimento neuropsicomotor e incapacidade para avaliar riscos, aliados ao comportamento curioso, as crianças se tornam mais suscetíveis aos acidentes ${ }^{(12)}$.

Também é a partir da adolescência e na idade jovem que se tem observado o crescimento dos índices de violência, não apenas como vítimas, mas também como infratores, em decorrência da maior exposição e vulnerabilidade inerentes a esta fase ${ }^{(22)}$.
Algumas características da personalidade infantil também são estudadas na busca de associação com os acidentes infantis. Alguns comportamentos como hiperatividade, agressividade, impulsividade e distração, assim como diferentes competências cognitivas, perceptivas, motoras e de linguagem, parecem estar presentes nas situações de causa acidental(23).

\section{Sexo da vítima}

O predomínio do sexo masculino entre as vitimas de acidentes ou violências também tem sido constantemente relatado. Uma reflexão sobre a masculinidade e a violência no Brasil, encontrou que, no período de 1991 a 2000, a taxa média de mortalidade masculina por causas externas foi de 119,6 por 100 mil habitantes, sendo cinco vezes maior do que a taxa média observada para as mulheres (24 por 100 mil habitantes) (22). Em Macapá, também há maior sobremortalidade masculina (10,3 mortes masculinas para cada óbito feminino). João Pessoa também apresenta um risco masculino (nove vezes maior que o feminino). Em outras capitais como Recife, Vitória, São Paulo e Cuiabá, observam-se taxas masculinas em torno de sete vezes maiores que as taxas femininas. No relatório de desenvolvimento juvenil, encontrou que praticamente $90 \%$ do total de óbitos juvenis por causas violentas são de homens ${ }^{(24)}$.

As representações históricas e constitutivas das culturas de gênero explicam, em grande parte, a maior vulnerabilidade dos homens em relação a esses agravos. Um fator cultural é a maior liberdade que é dada aos meninos e em compensação uma maior vigilância sobre as meninas. Outro fator diretamente ligado às mortes por homicídio e acidentes de transporte é o acesso mais fácil dos homens a arma de fogo e ao carro. Há que se ressaltar que a arma e o carro são inseridos na vida dos meninos desde criança como brinquedos e passam a fazer parte do seu cotidiano ${ }^{(22)}$.

\section{Etnia da vítima}

Alguns estudos brasileiros sobre a mortalidade por causas externas também têm apontado maior vitimização entre a população negra com maior perda de anos potenciais de vida por homicídio e acidentes de transporte entre os negros ${ }^{(25-26)}$. Estes são considerados vítimas de homicídio duas vezes mais que brancos ${ }^{(27)}$. A etnia em si não é considerada um fator de risco, mas a inserção social adversa de um grupo racial/étnico constitui característica de vulnerabilidade ${ }^{(28)}$. Estes últimos autores, por exemplo, verificaram a etnia como um importante marcador de desigualdade social, sendo a chance de morte entre negros aproximadamente quatro vezes maior que em brancos. As diferenças étnicas associam-se a desigualdades sociais e condicionam a forma de viver e de morrer de grupos populacionais.

Outro estudo(29), por exemplo, identificou diferencial no risco de mortalidade por homicídio segundo raça/cor e condição social. Indivíduos negros (pretos e pardos) associaram-se a pior condição social e maior risco de homicídio, comparados aos brancos.

\section{Uso de bebidas alcoólicas e substâncias químicas}

O uso de bebidas alcoólicas também é apontado por muitos autores como fator de risco para causas externas, principalmente 
em relação aos acidentes de trabalho, de transporte e aos episódios de violência (agressões, homicídios, suicídios) ${ }^{(29-33)}$. Estudo com vítimas de violências e acidentes atendidas em serviço de emergência, constatou que houve ingestão de álcool entre as vítimas de agressões $(39,1 \%)$, tentativas de suicídio $(25,4 \%)$, acidentes de transporte $(16,8 \%)$ e quedas $(5,9 \%)^{(34)}$.

Especificamente em relação à violência intencional, muitas pesquisas demonstram relação entre o uso de bebidas alcoólicas e de outras drogas com o comportamento violento ${ }^{(35-37)}$. Para muitos autores, o álcool e outras substâncias psicoativas funcionam como facilitadores de situações de violência, estando intimamente relacionadas com o comportamento violento ${ }^{(38-40)}$.

\section{Fatores biológicos}

Estes fatores são relatados na literatura exclusivamente em relação à violência intencional, pois estudos atuais de neurociência têm permitido elucidar os mecanismos biológicos (genéticos e neurofisiológicos) relacionados ao comportamento agressivo, levando à conclusão de que o comportamento violento e criminal não se deve apenas à fatores sociais e ambientais. O que as pesquisas têm demonstrado é que ocorre uma interação entre fatores socioambientais e fatores biológicos na produção da violência ${ }^{(17-18)}$.

Neste aspecto, estudos apontam que os fatores genéticos (baixa expressão do gene transportador de serotonina, bem como variações nos genes transportador e receptor de dopamina), juntamente com fatores sócio-econômicos-ambientais, tem relação com o desenvolvimento do comportamento $\operatorname{agressivo}^{(18,41-43)}$.

Os estudos sobre fatores biológicos também revelam a presença de fatores como a exposição a substâncias durante o desenvolvimento intrauterino (tabaco, álcool e cocaína) como de risco para o comportamento violento, bem como a desnutrição infantil(44-45).

\section{Fatores multicausais}

Apesar desta divisão didática de fatores de risco, muitos autores compreendem a mortalidade por causas externas como um problema de etiologia multifatorial, envolvendo desde o nível individual até o social, apontando algumas características associadas a estas causas, tais como: a idade jovem $^{(14-15,46-47)}$, o sexo masculino ${ }^{(48-50)}$, a etnia negra ${ }^{(26,51)}$, o baixo nível socioeconômico, de escolaridade e cultural (21,52-53), o nível de urbanização ${ }^{(7)}$. Desta forma, os óbitos por causas violentas entre a faixa etária mais jovem, de baixas condições socioeconômicas e com níveis de escolaridade baixos, são relatados por muitos autores como uma complexa rede de fatores que envolvem as mortes por causas externas ${ }^{(52,54)}$.

Especificamente em relação aos acidentes, o comportamento da família, o estilo de vida, a supervisão inadequada sobre a criança, os fatores educacionais, econômicos, sociais e culturais, além das características relativas à criança (fase de desenvolvimento, curiosidade e comportamento) e as condições do ambiente, guardam relação direta com os eventos não intencionais ${ }^{(55)}$.

Quanto à violência intencional, autores apontam para a interação de diversos fatores facilitadores para a produção da violência, tais como: fatores sócio-demográficos (sexo, área de moradia, nível sócio-econômico); familiares (nível educacional, violência familiar); psicológicos individuais (autoestima, depressão, consumo de álcool e drogas) ${ }^{(56)}$, uma vez que as principais vítimas são os jovens de classe pobre, em especial os do sexo masculino ${ }^{(57)}$.

Neste sentido, para compreender e explicar os fatores de risco de todos os tipos de injúrias (não intencionais, violências e suicídio), Blank ${ }^{(58)}$ associa o modelo epidemiológico de Uri Bronfenbrenner adaptado por Runyan ${ }^{(59)}$ e Saluja et $\mathrm{al}^{(60)}$, os quais integram a este modelo o contexto das injúrias físicas. Esta proposta leva em consideração os fatores de cada nível da estrutura socioambiental, ou seja: os fatores culturais, institucionais, interpessoais e intrapessoais, dentro de um ambiente físico-social. Entre os fatores intrapessoais, estaria o comportamento explorador ingênuo da criança pequena e a tomada de riscos consciente do adolescente. Seria um fator interpessoal a interação entre um pai e seu filho, seja para protegê-lo ou expô-lo a riscos. Como fatores institucionais, teríamos as instâncias em que os indivíduos interagem com a comunidade, tais como a escola e o trabalho. Por fim, os fatores culturais incluem uma série ampla de valores e normas sociais, bem como as políticas governamentais e a legislação ${ }^{(59-60)}$.

\section{Fatores de proteção e de vulnerabilidade}

Estudo ainda classifica os fatores associados às causas externas como fatores de resiliência (de proteção) e fatores de vulnerabilidade ${ }^{(58)}$.

Entre os fatores de vulnerabilidade estão: estresses cotidianos, doença ou perda de um dos pais, pobreza, desigualdades sociais, racismo, escolas deficientes, isolamento social, falta de afeto, violência urbana e as guerras.

Já os fatores de resiliência seriam: família estável, afeto, valorização da criança como prioridade, valorização da saúde como prioridade, proteção da criança contra estresses cotidianos, comunicação efetiva, modelos competentes de cuidado, fontes de apoio social, escolas de qualidade, recursos na vizinhança, educação no trânsito, entre outros. Alguns autores como fatores de resiliência, ainda, algumas medidas de proteção da criança em relação ao ambiente doméstico, tais como: portão em escada, grade em janela, grade em piscina, alarme de fumaça, hábitos de guardar fora do alcance da criança objetos pérfuro-cortantes e produtos em geral, cuidado com animais, além da supervisão direta sobre a criança, o que pode reduzir consideravelmente os eventos acidentais, inclusive os fatais ${ }^{(59,61)}$.

Neste sentido, a existência de uma rede de apoio social e afetiva, bem como orientações de prevenção e redução de riscos, é apontada como indicador de proteção contra as causas acidentais e intencionais.

Entretanto, é preciso considerar que a falta de articulação dos fatores de proteção, aliada à intensidade e diversidade dos fatores de risco, produzem uma dinâmica ainda geradora dos eventos externos, muitas vezes fatais ${ }^{(62)}$. Diante disto, torna-se essencial compreender essa dinâmica a fim de possibilitar a realização de ações educacionais e de saúde que visem a inibir e prevenir as causas externas, tanto a acidental como a intencional. 


\section{CONCLUSÃO}

A literatura aponta para a importância de intervir junto aos fatores de risco a fim de reduzir a morbidade e mortalidade por causa externas. O conhecimento dos fatores de risco discutidos ao longo deste texto possibilita subsidiar a prática dos atores sociais engajados na transformação das condições geradoras de acidentes e violências.
Sugerimos, ainda, novos estudos que aprofundem e relacionem os fatores de risco e de proteção relacionados às causas externas no sentido de produzir informações que mostrem, efetivamente, qual a dimensão do problema, quais são os grupos mais vulneráveis, onde eles se localizam, quais os fatores envolvidos, entre outras variáveis. Tais informações podem ajudar a produzir ações mais eficientes de combate às causas externas.

\section{REFERÊNCIAS}

1. Gawryszewski VP, Kanh T, Mello Jorge MHP. Informações sobre homicídios e sua integração com o setor saúde e segurança pública. Rev Saúde Pública 2005;39(4):627-33.

2. Silva $C A B$. A violência de todas as formas: um problema de saúde coletiva. Rev Bras Promoç Saúde 2006;19(1):1-2.

3. Minayo MCS. Seis características das mortes violentas no Brasil. Rev Bras Estud Popul 2009;26(1):135-40.

4. Dias Júnior CS. Quanto se ganha, em anos de vida, na ausência da mortalidade por causas externas e homicídios? Uma análise de 5 regiões metropolitanas do Brasil. Rev Bras Promoç Saúde 2007;20(3):150-4.

5. Santos JLG, Garlet ER, Figueira RB, Lima SBS, Prochnow AG. Acidentes e Violências: caracterização dos atendimentos no pronto-socorro de um hospital universitário. Saúde Soc 2008;17(3):211-8.

6. Secretaria de Estado da Saúde de São Paulo. O impacto dos acidentes e violências nos gastos da saúde. Rev Saúde Pública 2006;40(3):553-6.

7. Waksman RD. Redução de lesões por causas externas: o pediatra pode intervir? J Pediatr (Rio J.) 2004:80(6):435-6.

8. Paes CEN, Gaspar VLV. As injúrias não intencionais no ambiente domiciliar: a casa segura. J Pediatr (Rio J.) 2005;81(5 Suppl):S146-54.

9. Oliveira ZAR, Bettiol H, Gutierrez MRP, Silva AAM, Barbieri MA. Factors associated with infant and adolescent mortality. Braz J Med Biol Res 2007;40(9):1245-55.

10. Kanchan T, Menezes RG. Mortalities among children and adolescents in Manipal, Southern India. J Trauma 2008;64(6):1600-7.

11. World Health Organization [homepage na internet]. World report on child injury prevention. [acesso em 15 out 2010]. Disponível em: http://whqlibdoc.who.int/publications/2008/9789241563574_eng.pdf

12. Bem MAM, Silva Júnior JL, Souza JA, Araújo EJ, Pereima ML, Quaresma ER. Epidemiologia dos pequenos traumas em crianças atendidas no Hospital Infantil Joana de Gusmão. ACM Arq Catarin Med 2008;37(2):59-66.

13. Gilbride SJ, Wild C, Wilson DR, Svenson LW, Spady DW. Socio-economic status and types of childhood injury in Alberta: a population based study. BMC Pediatric 2006;6(30):1471-81.

14. Martins CBG, Andrade SM. Causas externas entre menores de 15 anos em cidade do sul do Brasil: atendimentos em pronto-socorro, internações e óbitos. Rev Bras Epidemiol 2005;8(2):194-204.

15. Nagaraja J, Menkedick J, Phelan KJ, Ashley P, Zhang X, Lanphear BP. Deaths From Residential Injuries in US Children and Adolescents, 1985-1997. Pediatrics 2005;116(2); 454-61.

16. O'Connor TG, Davies L, Dunn J, Golding J. Distribution of Accidents, Injuries, and IIInesses by Family Type. Pediatrics 2000;106(5):E68.

17. Kotch JB, Lewis T, Hussey JM, English D, Thompson R, Litrownik AJ et al. Importance of early neglect for childhood aggression. Pediatrics 2008;121(4):725-31.

18. Mendes DD, Mari JJ, Singer M, Barros GM, Mello AF. Estudo de revisão dos fatores biológicos, sociais e ambientais associados com o comportamento agressivo. Rev Bras Psiquiatr 2009;31(Suppl 2):S77-85.

19. Martins CBG, Andrade SM, Paiva PAB. Envenenamentos acidentais entre menores de 15 anos em município da Região Sul do Brasil. Cad Saúde Pública 2006;22(2):407-14.

20. Martins CBG. Acidentes na infância e adolescência: uma revisão bibliográfica. Rev Bras Enferm 2006;59(3):344-348.

21. Phebo L, Moura ATMS. Violência urbana: um desafio para o pediatra J Pediatr (Rio J.) 2005;81(5 Suppl):S187-196.

22. Souza ER. Masculinidade e violência no Brasil: contribuições para a reflexão no campo da saúde. Ciênc Saúde Coletiva 2005;10(1):59-70.

23. Baracat ECE, Paraschin K, Nogueira RJN, Reis MC, Fraga AMA, Sperotto G. Acidentes com crianças e sua evolução na região de Campinas, SP. J Pediatr (Rio J.) 2000;76(5):368-74

24. Waiselfisz JJ. Relatório de Desenvolvimento Juvenil, 2007. Brasília: RITLA; 2007. p. 91-114.

25. Batista LE, Escuder MML, Pereira JCR. A cor da morte: causas de óbito segundo as características de raça no Estado de São Paulo, 1999 a 2001. Rev Saúde Pública 2004;38(5):630-6.

26. Araújo EM, Costa MCN, Hogan VK, Mota ELA, Araújo TM, Oliveira NF. Diferenciais de raça/cor da pele em anos potenciais de vida perdidos por causas externas. Rev Saúde Pública 2009;43(3):405-12.

27. Ministério da Saúde. Temático prevenção de violência e cultura de paz V. III. Painel de indicadores do SUS [periódico 
na internet]. 2008 Nov. [acesso em 15 out 2010];1(5):1-60. Disponível em: http://bvsms.saude.gov.br/bvs/publicacoes/ painel_indicadores_sus_n5_p1.pdf

28. Bastos MJRP, Pereira JA, Smarzaro DC, Costa EF, Bossanel $\mathrm{RCL}$, Oliosa DMS et al. Análise ecológica dos acidentes e da violência letal em Vitória, ES. Rev Saúde Pública 2009;43(1):123-32.

29. Soares Filho AM, Souza MFM, Gazal-Carvalho C, Malta DC, Alencar AP, Silva MMA, Morais Neto OL. Análise da mortalidade por homicídios no Brasil. Epidemiol Serv Saúde 2007;16(1):7-18.

30. Barros MBA, Marín-León L, Oliveira HB, Dalgalarrondo P, Botega NJ. Perfil do consumo de bebidas alcoólicas: diferenças sociais e demográficas no Município de Campinas, Estado de São Paulo, Brasil, 2003. Epidemiol Serv Saúde 2008;17(4):259-270.

31. Gazal-Carvalho C, Carlini-Cotrim B, Silva OA, Sauaia N. Prevalência de alcoolemia em vítimas de causas externas admitidas em centro urbano de atenção ao trauma. Rev Saúde Pública 2002;36(1):47-54.

32. Abreu AMM, Lima JMB, Griep RH. Acidentes de trânsito e a freqüência dos exames de alcoolemia com vítimas fatais na cidade do Rio de Janeiro. Esc Anna Nery Rev Enferm 2009;13(1):44-50.

33. Abreu AMM, Lima JMB, Alves TA. O impacto do álcool na mortalidade em acidentes de trânsito: uma questão de saúde pública. Esc Anna Nery Rev Enferm 2006;10(1):87-94.

34. Mascarenhas MDM, Malta DC, Silva MMA, Carvalho CG, Monteiro RA, Morais Neto OL. Consumo de álcool entre vítimas de acidentes e violências atendidas em serviços de emergência no Brasil, 2006 e 2007. Ciênc Saúde Coletiva 2009;14(5):1789-96.

35. Melo EM, Faria HP, Melo MAM, Chaves AB, Machado GP. Projeto Meninos do Rio: mundo da vida, adolescência e riscos de saúde. Cad Saúde Pública 2005;21(1):39-48.

36. Morojele NK, Brook JS. Substance use and multiple victimisation among adolescents in South Africa. Addict Behav 2006;31(7):1163-76.

37. Moreira TC, Belmonte EL, Vieira FR, Noto AR, Ferigolo $M$, Barros HMT. A violência comunitária e o abuso de álcool entre adolescentes: comparação entre sexos. J Pediatr (Rio J.) 2008;84(3):244-50.

38. Kim HS, Kim HS. Gender differences in delinquent behavior among Korean adolescents. Child Psychiatry Hum Dev 2005;35(4):325-45.

39. Lennings CJ ,Kenny DT, Nelson P. Substance abuse and treatment seeking in young offenders on community orders. J Subst Abuse Treat 2006;31(4):425-32.

40. Heim J, Andrade AG. Efeitos do uso do álcool e das drogas ilícitas no comportamento de adolescentes de risco: uma revisão das publicações científicas entre 1997 e 2007. Rev Psiq Clín 2008;35(Suppl 1):61-4.

41. Widom CS, Brzustowicz LM. MAOA and the "cycle of violence:" chidhood abuse and neglect, MAOA genotype, and risk for violent and antisocial behavior. Biol Psychiatr 2006;60(7):684-9.
42. Beitchman JH, Baldassarra L, Mik H, De Luca V, King N, Bender D, et al. Serotonin transporter polymorphisms and persistent, pervasive childhood aggression. Am J Psychiatr 2006;163(6):1103-5.

43. Guo G, Roettger ME, Shih JC. Contributions of the DAT1 and DRD2 genes to serious and violence delinquency among adolescents and young adults. Hum Genet 2007;121(1):125-36.

44. Delaney-Black V, Covington C, Templin T, Ager J, Nordstrom-Klee B, Martier S, Leddick L, Czerwinski RH, Sokol RJ. Teacher-assessed behavior of children prenatally exposed to cocaine. Pediatrics 2000;106(4):782-91.

45. Liu JH, Raine A, Venables P, Dalais C Mednick SA. Malnutrition at ages 3 years predisposes to externalizing behavior problems at ages 8, 11 and 17 years. Am J Psychiatry 2004;161(11):2005-13.

46. Souza ER, Lima MLC. Panorama da violência urbana no Brasil e suas capitais. Ciênc Saúde Coletiva 2006;11(Suppl):1211-22.

47. Cardona D, Peláez E, Aidar T, Ribotta B, Alvarez MF. Mortalidad por causas externas em tres ciudades latinoamericanas: Córdoba (Argentina), Campinas (Brasil) y Medellín (Colômbia), 1980-2005. Rev Bras Estud Popul 2008;25(2):335-52.

48. Fraga AM, Fraga GP, Stanley C, Costantini TW, Coimbra R. Children at danger: injury fatalities among children in San Diego County. Eur J Epidemiol 2010;25(3):211-7.

49. Duarte EC, Tauil PL, Duarte E, Sousa MC, Monteiro RA. Mortalidade por acidentes de transporte terrestre e homicídios em homens jovens das capitais das Regiões Norte e Centro-Oeste do Brasil, 1980-2005. Epidemiol Serv Saúde 2008;17(1):7-20.

50. Andrade SMO, Pontes ERJC, Contini MLJ, Gomes AM, Nachif MCA. Vítimas da Violência em Campo Grande: um retrato de seis anos revelado pelos dados oficiais. Saúde Soc 2008;17(3):201-10.

51. Costa IER, Ludermir AB, Silva IA. Diferenciais da mortalidade por violência contra adolescentes segundo estrato de condição de vida e raça/cor na cidade de Recife. Ciênc Saúde Coletiva 2009;14(5):1781-1788.

52. Costa IER, Ludermir AB, Avelar I. Violência contra adolescentes: diferenciais segundo estratos de condição de vida e sexo. Ciênc Saúde Coletiva 2007;12(5):1193-200.

53. Soares Filho AM, Souza MFM, Gazal-Carvalho C, Malta DC, Alencar AP, Silva MMA, et al. Análise da mortalidade por homicídios no Brasil. Epidemiol Serv Saúde 2007;16(1):7-18.

54. Rivera-Rivera L, Allen B, Thrasher JF, Chavez R, Fernandez-Ortega C, Galal O, et al. Intra-familial physical violence among Mexican and Egyptian youth. Rev Saúde Pública 2005;39(5):709-15.

55. Souza LJEX, Rodrigues AKC, Barroso MGT. A família vivenciando o acidente doméstico - relato de uma experiência. Rev Latino-Am Enferm 2000;8(1):83-9.

56. Chavez Ayala R, Rivera-Rivera L, Angeles-Llerenas A, Díaz-Cerón E, Allen-Leigh B, Lazcano Ponce E. Factores del abuso sexual en la niñez y la adolescencia en estudiantes 
de Morelos, Mexico. Rev Saúde Pública 2009;43(3):506-14.

57. Taquette SR, Ruzany MH, Meirelles Z, Ricardo I. Relacionamento violento na adolescência e risco de DST/AIDS. Cad Saúde Pública 2003;19(5):1437-44.

58. Blank D. Controle de injúrias sob a ótica da pediatria contextual. J Pediatr (Rio J.) 2005;81(5 Suppl):S123-36.

59. Runyan CW. Introduction: back to the future - revisiting Haddon's conceptualization of injury epidemiology and prevention. Epidemiol Rev 2003;25(1):60-4.
60. Saluja G, Brenner R, Morrongiello BA, Haynie D, Rivera $M$, Cheng TL. The role of supervision in child injury risk: definition, conceptual and measurement issues. Inj Control Saf Promot 2004;11(1):17-22.

61. Britton JW. Kids can't fly: preventing fall injuries in children. Wis Med J 2005;104(1):33-6.

62. Antoni C, Barone LR, Koller SH. Indicadores de Risco e de Proteção em famílias fisicamente abusivas. Psic Teor Pesq 2007;23(2):125-32. 